From: Amanda Smith, Senior Lecturer in International Studies, Nottingham Trent University, School of Arts and Humanities, Clifton Campus, Nottingham, NG11 8NS. Tel: 01158486303. Email: amanda.smith02@ntu.ac.uk

\title{
The Transition Town Network: a review of current evolutions and renaissance
}

The Transition Network started as a movement with Transition Totnes (Devon, UK) in late 2005, with Rob Hopkins as its founder. To date it has grown to encompass 313 official Transition Network initiatives spread across the world from the UK (with roughly $50 \%$ of all initiatives) to the USA, Canada, Italy, Japan, Germany, Ireland, New Zealand, Chile, the Netherlands, Brazil and so on (Transition Network, 2010a). For any social movement, this could most certainly be described as something of a success and warrants a closer examination. Indeed, the aim of this profile is to explore the movement's aims and modus operandi, the problematics it has faced and how it is now evolving. The profile draws on my auto-ethnographic encounters with the movement in Transition Nottingham and at the recent Transition Network Conference 2010 , whilst also being grounded in the material made publically available on the Transition Network and Transition Culture websites (see Transition Network, 2010b and Transition Culture, 2010a).

The movement focuses upon supporting 'community-led responses to peak oil and climate change, building resilience and happiness' (Hopkins and Lipman, 2009:7), and is based on four assumptions:

1) That life with dramatically lower energy consumption is inevitable, and that it's better to plan for it than be taken by surprise.

2) That our settlements and communities presently lack the resilience to enable them to weather the severe energy shocks that will accompany peak oil.

3) That we have to act collectively, and we have to act now.

4) That by unleashing the collective genius of those around us to creatively and proactively design our energy descent, we can build ways of living that are more connected, more enriching and that recognise the biological limits of our planet.

(Hopkins, 2008:134). 
Ultimately, the essence of a Transition initiative is grounded in the concept of re-

localisation and resilience where,

'Rebuilding local agriculture and food production, localising energy production, rethinking healthcare, rediscovering local building materials in the context of zero energy building, rethinking how we manage waste, all build resilience and offer the potential for an extraordinary renaissance- economic, cultural and spiritual'. (op cit:15-emphasis added)

Communities are invited to set up official Transition initiatives by agreeing to 16 criteria, which are a blend of knowledge, skills, communication, working parameters and constitutional aims (Transition Network, 2010c). They also have access to the Transition Network website for information on the movement and many people in the movement have considered the publication The Transition Handbook in 2008 by Rob Hopkins somewhat of a 'manual' to doing Transition. In addition, the movement advocated 12 steps (or later described as ingredients) to embarking on a Transition journey.

1. Set up a steering group and design its demise from the outset

2. Awareness raising

3. Lay the foundations

4. Organise a Great Unleashing

5. Form sub groups

6. Use Open Space

7. Develop visible practical manifestations of the project

8. Facilitate the Great Reskilling

9. Build a bridge to Local Government

10. Honour the elders

11. Let it go where it wants to go...

12. Create an Energy Descent Plan

There have been many 'successes' for the movement, not least the rapidity and reach of its growth. For instance, Ed Milliband (then UK Secretary of State for Energy and Climate Change) attended the 2009 Transition Network conference as a 'keynote listener'; the Transition Handbook was voted fifth best book to take on holiday by MPs in the summer of 2009; three local currencies have been launched in England (in Totnes, Lewes and Brixton); Transition Town Totnes recently launched its Energy Descent Action Plan- Transition in Action; and the Scottish Assembly awarded a grant out of its Low Carbon Communities Fund to enable the 
establishment of a national Transition hub- Transition Support Scotland. These 'successes' notwithstanding the movement has been subject to critique from within and outwith. In the next section I will sketch out some of the key critiques associated with 'doing' Transition, and I would stress that these are based not only on academic critique but also auto-ethnographic experiences of working within the movement. In addition, I provide comment on how the Transition Network could be seen to be evolving and responding to some of these critiques.

\section{Problematics of 'Doing' Transition and Evolutions from within}

The overriding grand narrative for compelling actions and galvanising community responses towards Transition is the story of climate change and peak oil, or perhaps more bluntly- the addiction to cheap oil and how this may impact upon us when scarcity ensues and prices rise. This is indeed a compelling narrative and the raison d'être of much of the Transition awareness raising is grounded in the discourse of an apocalyptic future where resource scarcity and climate change have significantly altered societies. As a solution (antidote) to this future the Transition model of local resilience is presented as an ascensionist narrative (a tale with progressive theme, as opposed to declenist, with a tale of ultimate decline), such that communities will be much better prepared to weather shocks, their collapse will be prevented and people will be happier because they are no longer addicted to oil (and in turnconsumerism). The initial deployment of this grand narrative, and associated 'twelve steps', was deemed necessary to enabling communities to embark on a transition. Essentially, they provided a set of guiding principles (ingredients) and positive steps to allow communities to start to move forward under a banner of 'Transition Network'.

However, the problem with any grand narrative is that it is open to much contestation and many post-modernists would reject such over-arching discourses. Galvanising communities around the discourses of peak oil and climate change will inevitably be 
problematic when they are so contested as narratives; however, the movement seems to have encountered a more mobilising narrative in the 'financial crisis'. Indeed, the one session above all others that got people talking and the 2010 Transition Conference particularly animated was the talk by Stoneleighi about the immediacy of the financial crisis and how peak oil and climate change are inextricably linked to this (Stoneleigh, 2010). Indeed, the financial crisis is most certainly a more pressing narrative for the average person in any community and the Transition's failure to place the crisis centre stage thus far has perhaps hampered its progress. Asking individuals to consider a post-peak oil society is complex, asking them to engage with the notion of 'living on half your current income' (in a resources scarce landscape) is perhaps more immediate, thought provoking and likely to bring about engagement in the movement. Undeniably, those at the centre of the movement and the key claims makers of its discourses were clearly debating and trying to grapple with how narratives of financial crisis can be woven into the Transition movement more fully (see Smith, forthcoming, for more on discourses and claims makers). Much of the remainder of the conference was cast in the light of the 'Stoneleigh' financial crisis talk.

In attempting to maintaining a grand narrative, set centrally by the Network, the movement is always in danger of undermining its core beliefs- that of espousing creative community/bottom up responses to the issues. Not only is there a centrally set grand narrative but also a fairly formalised set of criteria for becoming an 'official' Transition initiative. In many ways this might stifle the creativity the movement seeks to embody, as it effectively imposes an artificial management model on local initiatives - the official joining criteria require 4-5 people in an initiating group who will step into leadership roles; 2 to attend the official Transition Network training course; a commitment to network and work with others, including the local council, other Transition initiatives and the Transition Network and so on. All of which formalises 
the initial grouping, giving them status (branding them) as part of the Transition Network but perhaps more importantly allowing them to be 'understood' by those operating in a neoliberal regime- namely local government and other funding bodies. In many ways it could be argued that the initiatives are mainstreamed into the wider neoliberal regime and become like many other third sector groups (see Smith, 2010). For people interested in the movement at the local level there can be a perception that it is 'not activist enough'- people want to get on and 'do things' and this managerialist approach can take time and considerable resources. I have also encountered people who consider the movement something of a cult, especially with the need to join and be trained in the ways of the Network and the 12 step approach (drawing obvious parallels to alcoholics anonymous).

These issues associated with levels of governance and community-based rhetoric are further compounded when one considers Step 9 of the Transition journey- build a bridge to local government. If a community group involves local government there exists a distinct risk that politics and issues of co-option into co-production take centre stage, further diverging the movement from its core rhetoric. Indeed, the notion of working with local government (and even central government as the wider Transition Network has) seems somewhat of an oxymoron for a social movement (particularly one that also advocates flexibility and organic growth -see step 11 above). Notionally, the Transition Network claims to work in an un-political and noncampaigning manner- a tacit agreement to 'not rock the boat'. However, this apolitical approach is fraught with contradictions and has led to a number of local Transition initiatives engaging in ideological debates that have in turn resulted in delays, loss of membership and lack of focus.

Indeed, when considering membership within the movement we encounter another major problematic for the Transition Network and its official initiatives face- that of 
membership diversity, or rather lack of it. This was highlighted during the 2009 Transition Conference and attempts have been made to address this with the Transition Network Diversity Project, which recently asked initiatives-'Have you ever looked around your local Transition meeting and wondered why most people involved are white, middle-class with an under or post-graduate degree?' (Transition Network, 2010d). Indeed, preliminary findings from a recent survey run by the project suggest that $95 \%$ of the respondents described themselves as white European and $86 \%$ were educated to degree of post-graduate level. The project is now aimed at broadening the Transition movement by working with low-income, faith and black minority ethnic groups. Indeed, my experience ii $^{\text {of }}$ working with Transition Nottingham has been that these groups are very much under-represented, and that trying to 'do Transition' in deprived communities most certainly requires a rethink of the grand narrative and 12 steps. Furthermore, to build truly resilient communities all members of the community will need to be involved.

Perhaps the biggest problematic of 'doing' Transition has been that of scale. What has worked well for a town the size (and demographic) of Totnes has not always scaled up (or even down) well. Urban transitions seem particularly challenging and following the steps and criteria of an 'official' Transition are far from straightforward. When commencing a Transition initiative in an urban setting the initiators will be vexed by the conundrum of 'which community'? I admit community is a slippery term at the best of times (geography, interest, faith and so on), but an urban area is composed of far more communities than a market town or rural village. Across the UK, urban Transitioners have taken a number of approaches to organising themselves across cities and conurbations. For instance, in London, Edinburgh, and Liverpool the initiatives have formed at a sub-scale of some sort. In London groups have formed in areas such as Brixton, Peckham, Tooting and so on, and it has only be very recently that there have been attempts to bring groups together to discuss 
Transition in Greater London (see Transition London, 2010). Whilst some other urban Transition groups have chosen to focus solely at a central and strategic scale, such as Leicester, which works with local government, has established regular Transition cafes and so on. Whereas, in Nottingham the Transition began as a small group of people working at a central level, however, early momentum (after a talk giving by founder, Rob Hopkins) led to groups forming at lower scales in neighbourhoods, mostly in more affluent neighbourhoods, some of which were outside of the city ward boundary but within the wider conurbation, and a hub remaining at the city level. This Transition architecture has proved highly problematic for Nottingham (I have written in detail about this elsewhere, see Smith, forthcoming), with a confusion over roles and responsibilities, mistrust and general poor communication between all groups. Furthermore, it seems harder to get maintain a momentum of membership in urban areas and the issues of diversity are intensified due to wider demographics.

'Doing' Transition in Nottingham has also highlighted a major issue for Step 12 of the Transition- create an energy descent plan (often the acronym EDAP is used for this plan). As envisaged by the movement an EDAP 'sets out the vision of a powereddown, resilient, relocalised future, and then backcasts, in a series of practical steps, creating a map for getting from here to there. Every settlement's EDAP will be different' (Hopkins, 2008:172). As such the plan addresses issues such as energy supply, food production, economy, transport and so on. In Nottingham we have struggled to get individuals interested in working on an EDAP, and meetings that we have had have resulted in much debate but limited progress- largely due to differences of opinion over what a 'plan' is, what scale we should be working at and who would be involved in a city EDAP- neighbourhood Transition groups, the city council, the county council, the regional development agency, and initiatives of similar purpose (for instance, there are numerous 'Transition type' projects spread across the city, such as city farms, re-skilling projects, low carbon community 
initiatives and so on). In an attempt to deal with some of these issues we wrote to Rob Hopkins, who then posted our issues on his blog and invited comments from Transitioners across the globe (see Transition Culture, 2010b). Even a cursory glance at these comments would suggest that urban Transitions in other countries are finding similar problems when 'doing Transition'. Just creating the momentum of interest to start an EDAP in a city is demanding, let alone agreeing on scale and key actors. For instance, in his response to us Rob suggested we need roughly $10 \%$ of the population to have heard of Transition before we can embark on an EDAP, in Greater Nottingham that would amount to around 65,000 people- a figure that would take a considerable amount of awareness-raising to achieve, particularly when one considers that Transition Nottingham is running with a fairly small (engaged) membership (six people) at the moment.

\section{Towards the Extraordinary Renaissance}

At the recent annual Transition Network conference Rob unveiled a new 'approach' for Transition- Pattern Language, based on a seminal text by Alexander et al (1977). During a workshop Rob suggested that the movement has grown quickly in the past four years and experience of how people are 'doing Transition' at a variety of scales (including cities) has made it clear that a new way of 'doing' is needed (see Hopkins, 2010). In addition, he noted that the 12 steps approach is perhaps not the most effective means of communicating Transition, perhaps not least because Totnes has just reached step 12 and now needs a step 13 and so on. Rob suggests that Pattern Language feels more appropriate as a means of communication for the movement as in this language there are (he used this citation),

'entities called patterns. Each pattern describes a problem which occurs over and over again in our environment, and then describes the core of the solution to that problem, in such a way that you can use this solution a million times over, without ever doing it the same way twice' (Alexander et al, 1977:x) 
Rob suggested that pattern language is like the internet before the internet, each pattern (hyper)linking to others allowing us to see an overall picture yet act upon one pattern at a time with the others in mind. Rob has started a working draft of a Transition pattern language, this was presented in the conference handbook and the session (see Transition Culture, 2010c). There are six suggested sets of Transition patterns, each with a number of patterns within. The first provides patterns to allow individuals/groups to consider 'what we start with' and includes patterns that address the 'thinking tools, skills and personal qualities that appear to help in the early stage'; whilst, the second set of patterns focus on maintaining momentum; the third, encourages more strategic thinking; the fourth, look at outreach; the fifth consider strategic planning, including creating new infrastructures; and the sixth set asks 'what might it look like if Transition initiatives across the UK are so outrageously successful that they start to impact upon national policy and development?'.

This format of pattern language may well facilitate better communication of the multifaceted and complex nature of Transition and address some of the issues I have sketched out in this profile but more evolution(s) may be required before the extraordinary renaissance can be achieved. The movement has been popular and has come a long way in four years, but compare this to a social movement like the co-operative and it is very much in its infancy, it is still trying to find its way. Although, it would be fair to also note that the Transition Network does draws on and re-brand a number of other existing movements with longer histories, particularly that of permaculture, and thus has some greater longevity than initial examination might suggest, it is still appropriate to say that the movement is in a 'fledgling' state- still trying to find its wingsiii. There are a number of issues the movement needs to address, such as transition for whom, by whom, with whom and at what scale? It may be that the movement will need to relax its centrally set grand narrative(s) to allow for a truly bottom-up, creative, collective, relocalised renaissance. Furthermore, the 
nexus of engagement with neoliberal actors, organisations and structures perhaps

needs closer inspection to avoid co-option for co-production that could endanger the ethos of the movement. In optimistic conclusion, that the movement has shown signs of evolution from within can only be promising for what is (if we accept the underlying elements of the grand narrative) a movement that is so essential to our very future.

\section{References}

Alexander, C et al. (1977) A Pattern Language. New York: Oxford University Press. Hopkins, R (2008) The Transition Handbook: from oil dependency to local resilience. Totnes: Green Books.

Hopkins, R. \& Lipman, P. (2009) Who we are and what we do. Totnes: Transition Network Ltd.

Hopkins, R. (2010) 'Introducing Transition as a Pattern Language' available at http://sheffield.indymedia.org. uk/2010/06/453429.html [acessed June 2010]. London Transition (2010) 'London Transition' available at http://www.londontransition.org.uk/ [acessed June 2010].

Smith, A. (2010) 'The Third Sector, Regeneration and Sustainable Communities: 'rolling' with the New Labour agenda.' International Journal of Sociology and Social Policy Vol. 30(1/2) pp 48-65.

Smith, A. (forthcoming) 'Community-led urban transitions and resilience: performing Transition Towns in a city' in Bulkeley, $\mathrm{H}$ et al eds. Cities and Low Carbon Transitions. Routledge: London.

Stoneleigh (2010) 'Making Sense of the Financial Crisis in the era of Peak Oil', available at http://transitionradio.posterous. com/blog?page=2 [accessed June 2010]. Transition Culture (2010a) 'Transition Culture' available at http://transitionculture.org/ [accessed June 2010].

Transition Culture (2010b) 'Energy Descent Action Plans for cities: some thoughts...' available at http://transitionculture.org/2010/05/19/energy-descent-action-plans-forcities-some-thoughts/ [accessed June 2010].

Transition Culture (2010c) 'Conference Booklet' available at http://transitionculture.org/wp-content/uploads/Seeing-Transition-as-a-PatternLanguage-conference-booklet-latest-version-1.1..pdf accessed June 2010]. Transition Network (2010a) 'Transition Initiatives Directory 'available at http://www.transitionnetwork. org/initiatives [accessed June 2010].

Transition Network (2010b) 'About Transition Network' available at http://www.transitionnetwork. org/about [accessed June 2010].

Transition Network (2010c) 'Becoming Official' available at http://www.transitionnetwork.org/community/support/becoming-official [accessed June 2010].

Transition Network (2010d) 'Bringing Diversity to Transition' available at http://www.transitionnetwork.org/news/2010-04-06/bringing-diversity-transition [accessed June 2010].

\section{Biography- Amanda Smith}

I currently work at Nottingham Trent University, where I undertake research and teaching in the areas of urban resilience, sustainable communities and social adaptations to climate change. I am a member of Transition Nottingham, Transition 
Sneinton \& St.Anns and a company director for a third sector regeneration body in Nottingham- The Partnership Council.

\footnotetext{
${ }^{i}$ Stoneleigh is the name that Nicole Foss writes under for the blog 'The Automatic Earth'.

${ }^{\text {ii I }}$ am co-founder of Transition Sneinton and St.Anns, which focuses on two deprived communities in inner city Nottingham and a member of the Energy Descent Action Plan group for Transition Nottingham.

iii This was an analogy used by Transition Network member Sophy Banks during the recent Transition Network 2010conference to describe the current state of the movement- she likened it to a fledgling sparrow she saw trying to fly out of the car park at the conference venue and noted that the movement was a little like that- had not yet quite got there.
} 